\title{
El carácter social de la teología*
}

\author{
Francisco de Aquino Júnior, \\ Facultad Católica de Fortaleza
}

La problemática que vamos a abordar no se refiere simplemente al área de la teología que trata de cuestiones explícita y directamente sociales: moral social, teología moral social, teología social. Tampoco se refiere al "capítulo" de esa área de la teología que es la doctrina o enseñanza social de la Iglesia, formulada, sobre todo, en las encíclicas sociales. Y no se restringe a la teología de la liberación, en sus diversas configuraciones y formulaciones, aunque esta haya sido la teología que asumió de modo más explícito y consecuente su carácter social, siendo, por eso mismo, conocida como una teología socio-liberadora, aunque no pueda ser reducida a una teología de lo social ni a una teología social.

La problemática del carácter social de la teología se refiere a toda y a cualquier teología y no solo a aquella teología o aquella área de la teología que se ocupa de las cuestiones sociales. Toda teología es esencial y constitutivamente social, aunque no pueda ser reducida a lo que tenga de social. Es, sin duda, más que social, pero no puede dejar de ser social. Lo social es un carácter o una dimensión de la teología y, en cuanto tal, caracteriza y configura, bajo cierto aspecto, la teología y el propio quehacer en su totalidad.

A esta problemática nos dedicamos en este artículo. Nuestra pretensión es mostrar en qué sentido toda teología es social. Se trata, por tanto, de explicitar y formular de modo sistemático ese carácter o esa dimensión social de la teología. Para ello, comenzaremos tratando la dimensión social de la vida humana y del carácter social de la intelección humana para, finalmente, explicitar y formular el carácter social de la teología.

\section{Dimensión social de la vida humana}

Que la vida humana esté relacionada con lo social, que tenga algo de social y que sea una realidad social es algo que se acepta sin mayores dificultades, o

* Traducción al español de Aníbal Atalibal Lorca, S.J. 
mejor, es algo que se impone con tal fuerza y poder que no hay cómo negarlo: "Contra los hechos no hay argumentos". Es el poder de imponerse que tiene la realidad. El problema comienza cuando se trata de determinar en qué consiste precisamente lo social y en qué sentido se puede y se debe afirmar que la vida humana es una realidad social.

Ciertamente no podemos desarrollar aquí una problemática tan amplia y compleja como esta. Tampoco podemos esbozar de modo mínimamente panorámico las diversas posturas y formulaciones desarrolladas a lo largo de la historia. En todo caso, podemos al menos identificar, aunque sea caricaturescamente, tres posturas o tendencias que han marcado de modo decisivo la discusión sobre lo social de la vida humana, que de algún modo circunscribe el estado actual de la cuestión y que nos ayudará a explicitar, en la tradición filosófica zubiriana, en qué sentido hablamos de la dimensión social de la vida humana ${ }^{1}$.

Una primera postura o tendencia trata lo social como una especie de pacto o contrato entre individuos; como algo estatuido (estatuto) o instituido (institución) por los individuos en vista de la garantía y protección de intereses individuales. Se trata, pues, de un nexo o vínculo establecido por los individuos y para los individuos ${ }^{2}$. Esta postura parte del presupuesto de que "el individuo es una substancia plena y suficiente" y, consecuentemente, que "los individuos empiezan por bastarse a sí mismos, reposan elementalmente sobre sí mismos". Lo social, aquí, llegaría después y serviría apenas para la "consolidación o potenciación de eso que individualmente somos en tanto que suficientes" y/o para "asegurar en cierto modo la realidad substantiva del individuo para que no se aniquile con los otros" . Ahora bien, que los hombres y mujeres tengan intereses particulares y que establezcan pactos o contratos entre sí en vista de garantizar y proteger esos

1. Cf. Xavier Zubiri, Sobre el hombre, Madrid: Alianza Editorial, 1998, pp. 223-341; y Tres dimensiones del ser humano: individual, social, histórica, Madrid: Alianza Editorial, 2006, pp. 37-69; Ignacio Ellacuría, Filosofía de la realidad histórica, San Salvador: UCA Editores, 1999, pp. 177-314 y 380-394; Antonio González, Un solo mundo: la relevancia de Zubiri para la teoría social (disponible en www.bubok.es); Introducción a la práctica de la filosofía: texto de iniciación, San Salvador: UCA Editores, 2005, pp. 237-291.

2. Uno de los representantes más importantes de esa postura o tendencia es el filósofo inglés John Locke (1632-1704). Para él, "el objetivo capital y principal de la unión de los hombres en comunidades sociales y de su sumisión a gobiernos es la preservación de la propiedad" (John Locke, Segundo tratado sobre o governo civil. Ensaio sobre a origem, os limites e os fins verdadeiros do governo civil, Petrópolis: Vozes, 2006, IX, n. 124, p. 156. Sobre Locke, cf. Antonio González, Introducción a la práctica de la filosofia, op. cit., pp. 238-242; Manfredo Araújo de Oliveira, "Locke: a emergência do 'indivíduo livre' no horizonte do ético", en Ética e sociabilidade, São Paulo: Loyola, 1993, pp. 110-129).

3. Xavier Zubiri, Sobre el hombre, op. cit., p. 248. 
intereses es algo evidente. Mas que estos pactos o contratos constituyan el nexo o el vínculo social radical entre ellos y que exista un individuo natural previo a cualquier nexo o vínculo social es más que discutible. Primero, porque todos los individuos que conocemos, por más individuales o individualistas que sean, son individuos socialmente constituidos. Segundo, porque para que ellos puedan establecer un pacto o un contrato entre sí necesitan estar ya, de algún modo, vinculados unos con otros.

Una segunda postura o tendencia trata lo social como algo objetivo que tiene consistencia propia independientemente de los individuos, como un objeto dado, "una especie de realidad supraindividual que gravita sobre los individuos y los configura"4 por imposición, por presión, por imitación, por interacción, poco importa: "Un hombre habla la lengua que habla, tiene las costumbres y las ideas que tiene justamente porque una sociedad concreta se las ha inculcado. Incluso el más rebelde de los hombres recibe sus ideas de una sociedad determinada"5. Si para la primera postura o tendencia los individuos "crean la sociedad de modo voluntario y libre" (contrato, pacto), aquí, al contrario, "la sociedad crea los individuos" (imposición, presión, imitación, interacción) ${ }^{6}$; si allá lo social no existe sino en función de los intereses individuales, aquí los individuos prácticamente desaparecen en función de lo social". Ahora bien, que lo social "sea real

4. Ignacio Ellacuría, Filosofía de la realidad histórica, op. cit., p. 228.

5. Antonio González, Introducción a la práctica de la filosofía, op. cit., p. 243.

6. Ibidem.

7. "A lo largo de la historia de la filosofía estas ideas tuvieron muchos y diversos defensores. Uno de los más notables es, sin duda, el filósofo idealista alemán Wilhelm Friedrich Hegel" (1770-1831). Para él, "la realidad en su totalidad no es otra cosa que el desarrollo y plasmación de la Idea o Razón Universal" (ibidem). En esta perspectiva, "el individuo prácticamente desaparece [...]. Los individuos no son más que títeres encargados, ya de antemano, de representar un determinado papel [...]. Es más, la muerte, la miseria y la opresión de los individuos no dejan de ser caminos trágicos que la Razón tiene que tomar para realizarse en las luchas y conflictos de la Historia. Estamos en las antípodas de Locke: mientras para aquel la sociedad y el Estado son instrumentos al servicio de los individuos, para Hegel el individuo no es más que un medio que toma la historia para realizarse" (ibid., p. 245). Y es esto lo que está en el origen de la sociología como ciencia: el descubrimiento de la sociedad como realidad objetiva. Por más que la sociología haya nacido "en pugna con la filosofía en general y, más concretamente, con el idealismo especulativo de Hegel", tiene en común con él la comprensión de lo social como algo objetivo. Así como Hegel, todos los grandes fundadores de la sociología moderna (Saint-Simon, Comte, Marx, Durkheim) tratan la sociedad "como algo objetivo, anterior a los individuos" (ibid., p. 245). Ciertamente, esta no es la única lectura posible de Hegel. Hay quien defienda que, en su esfuerzo por superar "la 'postura solipsista' que caracteriza la filosofía moderna de la subjetividad", Hegel "intenta pensar dialécticamente lo que había sido separado por la filosofía de la modernidad: el derecho del individuo y el derecho 
y que como realidad sea irreductible a la suma de las realidades individuales y a la suma de las interacciones individuales no implica que sea una especie de realidad substantiva, en la cual los individuos fueran como miembros de un macroorganismo" ". Si por un lado, como afirmábamos, no existe un individuo natural previo a cualquier nexo o vínculo social, por otro lado, es preciso afirmar muy claramente que tampoco existe una realidad social objetiva independiente de los individuos concretos.

Una tercera postura o tendencia, desarrollada en diálogo crítico con las dos anteriores, procura superar tanto la posición individualista como la posición objetivista de lo social: lo social no es meramente fruto de un pacto o contrato entre individuos, pero tampoco es algo que flota sobre los individuos. No existe un individuo natural previo a cualquier nexo o vínculo social ni existe una realidad social anterior a todo y cualquier individuo. En realidad, la raíz del nexo o vínculo social

no es ajena a los individuos. La sociedad no flota sobre sí misma, sino que su substrato o su apoyo son los individuos, pero los individuos en cuanto están realmente vinculados entre sí con todo el haber humano. Esto es lo que confiere carácter físico y real a lo social sin darle carácter de unidad substancial independiente, de substancia que sea suficiente en sí misma, aunque sus componentes sean realidades individuales. ${ }^{9}$

En esta perspectiva, lo social aparece como una dimensión constitutiva de la vida y, en cuanto tal, como algo que mensura, bajo cierto aspecto, la vida humana en su totalidad. No es algo consecutivo a un supuesto estado natural-individual de la vida humana ni es algo previo a los individuos concretos. El problema, aquí, consiste en explicitar ese carácter dimensional del nexo o vínculo social, de modo que aparezca, simultáneamente, como algo constitutivo de la vida humana en su totalidad (ni consecutivo a ella ni independiente de ella) y como algo irre-

de la totalidad social". De modo que "individualidad y sociabilidad no pueden ser apenas consideradas como dimensiones yuxtapuestas, sino como dimensiones contradictorias que mutuamente se incluyen y se excluyen y por eso no pueden ser pensadas separadamente" (Manfredo Araújo de Oliveira, "Hegel: normatividade e eticidade", en Ética e sociabilidade, São Paulo: Loyola, 1992, pp. 198-226, aquí pp. 211 y s.). La cuestión es saber si tal pretensión de hecho es efectiva en su pensamiento o si su reacción a la "postura solipsista" no acabó de hecho conduciéndolo al otro extremo, más allá de sus pretensiones y de su conciencia. Valdría la pena, aquí, analizar su obra clásica Filosofía de la Historia (Cf. Friedrich Hegel, Filosofia da história, Brasilia: UnB, 2008). No obstante, eso extrapolaría de modo excesivo los límites de nuestro abordaje del tema.

8. Ignacio Ellacuría, Filosofía de la realidad histórica, op. cit., p. 228.

9. Ibid., pp. 229 y s. 
ductible en la vida humana (ni independiente de la vida humana concreta ni mera suma de individuos).

Para Zubiri, el nexo o vínculo social de la vida humana se da y se manifiesta en dos niveles o modos fundamentales. Se trata, ante todo, de un vínculo o nexo biológico. Todos los hombres y mujeres, en la medida que nacen unos de los otros, están genéticamente vinculados; pertenecen a la misma especie, al mismo phylum. Por su propia estructura biológica (código genético), los humanos se constituyen en respectividad entre sí, están vertidos entre sí. Antes de ser individuos, son miembros del tronco o phylum humano; su propia individualidad se inscribe y se constituye en esa pertenencia a la especie. Zubiri dice que "la raíz última de la versión de un hombre a otro, de los hombres entre sí, es una razón genética"10. Pero eso no es todo. Por esta versión de carácter genético, los humanos se encuentran en una situación común, comparten un mismo mundo humano, conviven unos con otros. Y ahí, precisamente, en esta "co-situación", en este "mundo humano" compartido, en esta "con-vivencia", se va dando el proceso de co-humanización de los individuos: modo de convivir y organizar la vida. Se trata de un proceso intrínsecamente social, en el cual los otros ya están metidos en la vida del niño incluso antes de que él pueda sospechar que haya otras personas en el mundo (nutrición y amparo), los cuales continúan presentes a lo largo de la vida, mucho más de lo que se piensa. El vínculo o nexo social se configura aquí, en palabras de Zubiri, como "constitución del mundo humano", como proceso de "co-humanización"11. En síntesis, los humanos están genética y humanamente vinculados unos con otros. Son, por su propia estructura biológica y por su propio proceso de humanización, seres esencial y constitutivamente sociales.

En el proceso de humanización, ellos se vinculan unos con otros y conviven entre sí, para bien o para mal, tanto de modo personal como de modo imper-

10. Xavier Zubiri, Tres dimensiones del ser humano, op. cit., p. 42.

11. Ibid., pp. 44 y s. "El progenitor va dando satisfacción de necesidades o tomando la iniciativa de dar cosas que piensa que aquel a quien cuida va a necesitar o le van a ayudar. Hay una mosca, se la puede espantar y así estamos todos tranquilos, etc. [...] en esos actos tan sencillos y tan elementales se produce algo mucho más profundo: a lo largo del tiempo [...] el niño va adquiriendo la conformación de lo que podríamos llamar el carácter 'humano' de su vida. Lo que viene desde fuera para el niño es más que la influencia de otra persona, es la conformación de su humanidad. Es una especie de co-situación de co-humanización. Va adquiriendo precisamente un mundo y un carácter humano" (ibid., p. 44). El carácter social de todo ese proceso de humanización tiene que ver precisamente con su condición de "publicidad". Se entiende, aquí, por publicidad "aquella condición de lo humano por la que este ámbito de lo humano está a la disposición de todos" (Ignacio Ellacuría, Filosofía de la realidad histórica, op. cit., p. 214). No se trata de "una propiedad real de las cosas mismas", sino de la "condición de las cosas" en cuanto se hacen accesible o no a los demás (ibid., p. 215). 
sonal $^{12}$. Por un lado, se vinculan y conviven en cuanto personas: "comunión personal". En este modo de convivencia (familia, amistad, vecindad, comunidad, etc.), las personas son absolutamente insustituibles. Él surge con las personas y desaparece cuando ellas desaparecen. Por otro lado, se vinculan y conviven con los otros impersonalmente: "sociedad". Aquí no cuenta la persona en cuanto persona, sino en cuanto impersonalizada, esto es, en cuanto reducida a otro, en cuanto ocupa un lugar y una función en la sociedad y, así, interviene, de algún modo, en la vida de los otros. Si en la convivencia personal las personas son absolutamente insustituibles, en la convivencia impersonal son perfectamente sustituibles, desde que se encuentre a alguien que desempeñe su función.

En un sentido bastante amplio, lo social dice respecto tanto a la "comunión personal" cuanto a la "sociedad". Pero, en sentido estricto, dice respecto únicamente a la sociedad. En ella, mujeres y hombres se hacen presentes y actúan en la vida de unos y otros - conviven - de modo impersonal, o sea, en cuanto persona reducida a la mera alteridad: "meros otros". Y esa reducción impersonal se va profundizando en la medida en que la sociedad va creciendo y se va complejizando a través de sus instituciones, organizaciones y modos de funcionamiento. Basta ver cómo se da el vínculo o nexo social en las grandes ciudades y en los procesos de modernización económico-tecnológicos (sistema financiero internacional, crisis ecológica, agro-hidro-negocio, Internet, etc.): cada vez menos las personas se vinculan entre sí de modo personal. Evidentemente, continúan vinculadas entre sí, interactúan e interfieren (más que nunca) en la vida unos de otros, pero de modo cada vez más impersonal, es decir, en cuanto personas reducidas a meros otros. La sociedad nos habla del modo impersonal (personas reducidas a meros otros) de vínculo y convivencia humanas. Ella consiste, dice Antonio González, en la organización y estructuración impersonal de las actividades de la especie humana de modo colectivo. Y tanto en lo que dice respecto a las actividades más propiamente económicas (producción y distribución de los bienes de utilidad), cuanto en lo que se refiere a las actividades predominantemente sociopolíticas (instituciones sociales de organización y control), y cuanto, aún, en lo que dice respecto a las actividades más típicamente cultural-ideológicas (ciencia, tecnología e ideología) ${ }^{13}$.

12. $C f$. Xavier Zubiri, Tres dimensiones del ser humano, op. cit., pp. 56-60. "Las acciones, en efecto, pueden considerarse desde dos puntos de vista. Ante todo, como momentos de una vida personal, esto es, como modos de poseerse a sí mismos como realidad 'suya' en el todo de lo real. Pero pueden considerarse no como momentos de la vida personal, sino 'reducidos' a ser acciones que pertenecen a la persona solo en el sentido de que se dan o tienen realidad en ella. En esta medida, no son acciones 'personales', sino tan solo de la persona; se dan en ella, pero nada más. Lo personal 'reducido' a ser de la persona: he aquí la esencia de lo impersonal” (ibid., p. 57).

13. Cf. Antonio González, Introducción a la práctica de la filosofía, op. cit., pp. 255-272. 
Conviene, por fin, insistir en el hecho de que el carácter impersonal de ese modo de vínculo o nexo social que es la sociedad, no la transforma en algo que flota por encima de las personas concretas y que sea absolutamente independiente de ellas. No existe la "sociedad en sí", como algo separado de las personas. Lo que existen son personas concretas vinculadas de modo impersonal unas con las otras y vinculadas de una forma o de otra. La organización y estructuración del vínculo social, la sociedad, es fruto de la interacción de las personas, en su colectividad, y por ellas es mantenida o puede ser transformada. No es algo que existe en sí, que es fruto de una casualidad, del destino, de una supuesta razón universal o determinación de Dios y que, por tanto, sea inalterable, intransformable. De modo que si la transformación social no es algo tan simple (¡querer no necesariamente es poder!), tampoco es algo imposible (¡siempre fue así y siempre será así!). Depende de la acción concreta de personas y grupos concretos, de la correlación de fuerzas que se va construyendo y de la viabilidad de las alternativas que se van descubriendo y forjando.

Por más irreductible que sea (y en eso Hegel y los fundadores de la sociología tienen razón), lo social no es sino una dimensión de la vida humana (y eso contra la posición individualista, así como contra la posición objetivista): la dimensión según la cual ella está intrínseca y esencialmente constituida en respectividad biológica (esquema o código genético) y humana (proceso de humanización) a las demás personas. En cuanto dimensión, lo social es constitutivo de la vida humana y no meramente consecutivo a ella, como piensa la postura individualista. Y en cuanto constitutivo, no es nada anterior, encima e independiente de las personas concretas, como piensa la postura objetivista. Es en este sentido, precisamente, que hablamos de lo social como una dimensión de la vida humana: algo que la constituye y, en cuanto tal, la mensura bajo cierto aspecto.

\section{El carácter social de la intelección humana}

Si lo social es una dimensión constitutiva de la vida humana y si la intelección es uno de los momentos o una de las notas esenciales de la vida humana, esa intelección será, necesariamente, social. Y en un triple sentido.

Primero, por ser nota o momento constitutivo de la vida humana ${ }^{14}$.

La inteligencia humana tiene, sin duda, una estructura propia, por la cual se diferencia de otras notas de la realidad humana; esa estructura propia permite

14. Cf. Xavier Zubiri, Sobre el hombre, op. cit., pp. 11-41; e Inteligencia sentiente. Inteligencia y realidad, Madrid: Alianza Editorial, 2006, pp. 281-285; Óscar Barroso Fernández, Verdad y acción: para pensar la praxis desde la inteligencia sentiente zubiriana, Granada: Comares, 2002; Francisco Aquino Júnior, A teologia como intelecção do reinado de Deus: o método da teologia da libertação segundo Ignácio Ellacuría, São Paulo: Loyola, 2010, pp. 238-245. 
una precisa especialización, irreductible a lo que es propio de otras notas de la realidad humana, de modo que solo la inteligencia intelige y lo que hacen otras notas es algo formalmente distinto de este inteligir. Pero lo que la inteligencia hace, por más formalmente irreductible que sea, lo hace en unidad primaria con todas las demás notas de la realidad humana. Por tanto, el reconocimiento de esta estructura propia no implica que se le atribuyan una substantividad y autonomía totales, pues siempre está condicionada y determinada por la primaria unidad que es el hombre como ser vivo. ${ }^{15}$

Y este, como vimos en el ítem anterior, es, por su propia estructura biológica y por su propio proceso de humanización, una realidad intrínseca y esencialmente social. De modo que la intelección, en cuanto momento o nota de la vida humana, es también algo intrínseca y esencialmente social. En otras palabras, en cuanto carácter y dimensión de la vida humana, lo social caracteriza y mensura la vida humana en su totalidad, inclusive en su momento más propiamente intelectivo.

Segundo, por ser intelección de realidades sociales o, en todo caso, de realidades inseridas de algún modo en la vida social. Por un lado, gran parte de la realidad con la que nos enfrentamos intelectivamente son realidades de orden estrictamente social (relaciones interpersonales, familiares y grupales, modos y reglas de convivencia, instituciones sociales, estructuras de gobierno, etc.) o realidades que tienen una dimensión social constitutiva (todo lo que dice respecto a la vida humana, en la medida en que esta tiene una dimensión social constitutiva: biología, psicología, economía, política, religión, etc.). Por otro lado, aun las realidades que no son de orden estrictamente social (mundo material, vegetal, fenómenos naturales, Dios, etc.) o que solo analógicamente o por extensión pueden serlo (mundo animal ${ }^{16}$ ), en cuanto aprendidas intelectivamente, son inse-

15. Ignacio Ellacuría, "Hacia una fundamentación del método teológico latinoamericano", en Escritos teológicos, I, San Salvador: UCA Editores, 2000, pp. 187-218, aquí pp. 206 y s.

16. Para Zubiri, no se puede hablar de modo estricto de sociedad animal. Entre animales no hay propiamente sociedad, sino apenas agrupación. Para que haya sociedad es necesario que el vínculo o nexo social sea vivido como algo "en propio", "de suyo", esto es, como "realidad". "El momento de realidad es lo que constituye el carácter radicalmente distintivo y propio de lo que es una sociedad frente a una agrupación de animales. Es lo que constituye el paso de la agrupación animal a la sociedad humana. Sociedad es una convivencia fundada expresa y formalmente en la realidad. Solo por extensión se puede hablar de sociedades animales. Inclusive en el caso de animal doméstico, no puede hablarse de una estricta sociedad. El perro está incorporado a la vida del hombre y a la sociedad humana, pero no como 'socio'. Es una incorporación a la sociedad, pero sin que haya esa con-vivencia social, bilateral, esencial para la sociedad (Xavier Zubiri, Tres dimensiones del ser humano, op. cit., p. 39). 
ridas en un ámbito de realidad intrínsecamente social y adquieren un sentido ${ }^{17}$ rigurosamente social. Mejor dicho, son aprendidas intelectivamente precisamente por estar inseridas en la vida humana y tener ahí algún significado. De modo que, por tratarse siempre de realidades sociales o de realidades de algún modo inserida en la vida social, la intelección tiene un carácter social indiscutible.

Tercero, por la propia dinámica del proceso intelectivo. No solo inteligimos realidades rigurosamente sociales o en todo caso inserida en un ámbito de la realidad social, sino que inteligimos socialmente. El propio proceso de intelección es estrictamente social. Sea en la medida en que se enfrenta con realidades sociales que, de alguna forma y en alguna medida, determinan su dinamismo (el modo de conocer una realidad cualquiera está determinado en gran parte por la constitución de esa realidad y por el modo como ella se deja aprender intelectivamente). Sea en la medida en que es posibilitado por estructuras intelectivas y por sistemas de conceptos socialmente desarrollados y mediados (el proceso intelectivo depende siempre de las posibilidades teóricas disponibles en cada lugar y en cada momento, y estas "se constituyen como resultado de una marcha histórica y representan el sustrato desde el cual se piensa"18). Sea en la medida en que responde a determinados intereses sociales, más o menos explícitos ("el conocer humano tiene una estricta dimensión social no solo por su origen, sino también por su destinación"19; dimensión esta que si no fuera explicitada y elaborada críticamente, conduciría fácilmente a ideologizaciones). Sea, finalmente, en la medida que se constituye como un estricto proceso de ideologización (en cuanto que no apenas responde a determinados intereses, sino que lo hace de modo camuflado, mascarando la realidad y presentándose como pura objetividad).

De modo que, en cuanto nota o momento constitutivo de la vida humana, en cuanto aprende realidades de algún modo sociales y en cuanto las aprehende socialmente, la intelección humana tiene un carácter intrínseca y estrictamente social. Y eso vale para cualquier actividad intelectiva. Consecuentemente, vale, mutatis mutandis, para esa actividad intelectiva específica que es la teología. Es lo que veremos a continuación.

17. "Sentido" se refiere al lugar y a la función que las cosas ocupan y desempeñan en la vida humana. Ciertamente, en el proceso de intelección las cosas son aprendidas, en última instancia, como "realidad", esto es, como algo que le pertenece "en propio", "de suyo", como algo que "actúa sobre las demás cosas o sobre sí mismo en virtud, formalmente, de las notas que posee". Pero, en cuanto aprendidas, pasan a ser parte de la vida humana y adquieren ahí un sentido (lugar, función) determinado. Es la distinción zubiriana entre "cosa-sentido" y "cosa-realidad" ( $C f$. Xavier Zubiri, Sobre la esencia, Madrid: Alianza Editorial, 1985, pp. 103-108; y El hombre y Dios, Madrid: Alianza Editorial, 2003, p. 19).

18. Ignacio Ellacuría, Filosofía de la realidad histórica, op. cit., p. 209.

19. Ibid., p. 211. 


\section{El carácter social de la teología}

Después de confrontarnos con la problemática de la dimensión social de la vida humana y del carácter social de la intelección humana, nos resta explicitar el carácter social de la teología, en cuanto actividad estrictamente intelectiva. Esto está relacionado con (1) el ámbito de realidad a ser inteligido por la teología, (2) con la finalidad o carácter interesado de la teología, (3) con el carácter eclesial/institucional de la teología, (4) con sus mediaciones teórico-conceptuales y (5) con su carácter conflictivo.

\section{1. Ámbito de realidad de la teología}

El carácter social de la teología hace referencia ante todo a su "ámbito de realidad" ${ }^{20}$, esto es, a la "totalidad concreta" y a la "historia" con la cual ella se enfrenta intelectivamente. Diferente de lo que se acostumbra a pensar y de lo que da a entender un abordaje meramente etimológico de la expresión (Theós = Dios y logia $=$ palabra), la teología no trata de Dios sin más. Trata de Dios, sí, en cuanto y en la medida en que se hace presente y actúa en la historia. Trata, por tanto, de la acción de Dios en la historia, que es siempre, de alguna forma y en alguna medida, reacción de Dios frente a determinadas situaciones y acontecimientos (salvación) e interacción con personas y pueblos concretos (pueblo de Dios-Iglesia). De ahí la insistencia de Ellacuría en que el asunto o el "objeto" de la teología cristiana no sea Dios sin más, sino el reinado de Dios ${ }^{21}$, tanto en lo que tiene de Dios como en lo que tiene de realización histórica de su reinado, pero en su unidad radical de reinado de Dios. No es casualidad que, cuando se trata de determinar el asunto (objeto) de la teología cristiana, se hable normalmente de revelación y fe: la teología trata de la revelación y de la fe cristiana ${ }^{22}$.

20. Ibid., p. 212. "Por ámbito de realidad entendemos aquí no un objeto o una serie de objetos, sino la totalidad concreta e histórica con que se enfrenta una determinada actividad [intelectiva, en el caso de la teología]" (ibidem). Sobre la problemática del "ámbito de realidad" de la teología, $c f$. Francisco Aquino Júnior, "O reinado de Deus como assunto da teologia cristã", REB, 281 (2011), pp. 47-68.

21. $C f$. Ignacio Ellacuría, "Fe y justicia", en Escritos teológicos, III, San Salvador: UCA Editores, 2002, pp. 307-373, aquí p. 311; "La teología como momento ideológico de la praxis eclesial", ibid., pp. 175 y s; "Relación teoría y praxis en la teología de la liberación”, ibid., pp. 235, 240 y s.; "Teología de la liberación frente al cambio sociohistórico en América Latina", en Escritos teológicos, I, pp. 313-345, aquí p. 315; "Aporte de la teología de la liberación a las religiones abrahámicas en la superación del individualismo y del positivismo", en Escritos teológicos, II, San Salvador: UCA Editores, 2000, pp. 193-232, aquí pp. 202 y s.

22. Cf. Edward Schillebeeckx, Revelação e teologia, São Paulo: Paulinas, 1968, pp. 86-96; Yves Congar, La foi et la théologie, Tournai: Desclée, 1962, pp. 127-132; João Bastita Libânio y Afonso Murad, Introdução à teologia: perfil, enfoques, tarefas, São Paulo: Loyola, 1996, pp. 67-75; Clodovis Boff, Teoria do método 
El propio Tomás de Aquino, hablando de Dios como asunto (subiectum) de la doctrina sagrada, es decir, "aquello de lo que se habla en esa ciencia", tiene que admitir que el conocimiento de Dios ("quién es él”) está mediado por los "efectos que él produce en el orden de la naturaleza o de la gracia” (STh I, q.1, a.7). De una forma o de otra, no hay cómo hablar de Dios sin hablar de la creación y, más concretamente, de la historia de la salvación. Y esta tiene una dimensión intrínseca y constitutivamente social. En un doble sentido. Por un lado, se refiere a la historia de personas y de pueblos concretos, cuya dimensión social es indiscutible $^{23}$. Por otro lado, produce o desencadena un dinamismo histórico-social con enormes implicaciones en los procesos de estructuración social y política de la sociedad ${ }^{24}$. De modo que la historia de la salvación, de la cual se ocupa la teología, más allá de darse en una historia social y política, tiene densidad e implicaciones sociales y políticas.

Pero eso no es todo, ya que podría ocurrir que, aunque tratando de una realidad que tiene una dimensión social constitutiva, la teología en cuanto tal, es decir, en cuanto actividad estrictamente intelectiva, no fuese, en sí misma, una realidad social y que entre el hacer teológico y la realidad a ser inteligida por la teología no se diese más que relación entre relatos que en sí y por sí nada tendría que ver con lo otro ${ }^{25}$. Ocurre que la intelección de una realidad cualquiera

teológico, Petrópolis: Vozes, 1998, pp. 110-195; Honório Rito, Introdução à teologia, Petrópolis: Vozes, 1999, pp. 37-52.

23. Por más que se quiera destacar ahí las relaciones biográficas y personales y el carácter personal de las relaciones de los hombres con Dios, no se puede olvidar el carácter social y político de esas vidas y relaciones, "cuyo peso es indudable en la propia configuración personal de la revelación de Dios al hombre y del encuentro del hombre con Dios" (Ignacio Ellacuría, "Fe y justicia", op. cit., pp. 318 y s.).

24. No se puede olvidar que "la constitución del pueblo de Israel es inseparable de la constitución de la revelación veterotestamentaria" (ibid., p. 319) ni que la revelación de Dios en Jesucristo es inseparable de su praxis del reinado de Dios y que esta tenía implicaciones y repercutía en la estructuración de las relaciones sociales y políticas de su tiempo. Se piensa, por ejemplo, en el contacto con los impuros (leprosos, samaritanos, etc.), en las curas los días sábados, en la comensalía con "pecadores", en la equiparación e incluso subordinación del amor a Dios al amor al prójimo, en los conflictos con las fuerzas políticas de su tiempo y, sobre todo, en su crucifixión.

25. Esa parece ser la tendencia de Clodovis Boff, en la medida que trata vida y pensamiento, teoría y práctica como realidades no apenas "distintas", sino verdaderamente "heterogéneas, aunque combinables" (Clodovis Boff, Teoria do método teológico, op. cit., p. 391; cf. ibid., pp. 112, 121, 168). "Las leyes del pensamiento y del lenguaje son diferentes a las de la realidad. El orden del ser no es el orden del conocer" (Clodovis Boff, Teologia e prática. Teologia do Político e suas mediações, p. 216; cf. ibid., p. 341). "Desde el punto de vista de la práctica de la teología, la praxis (política) no es ni puede ser criterio de verdad (teología). La razón es simple: es que la práctica política es de orden diferente a la práctica teórica. Por eso una no tiene que ver con 
está determinada, en buena medida, por la constitución de esa realidad y, consecuentemente, por el modo como ella se deja aprehender intelectivamente: la intelección de una realidad de carácter biológico es distinta a la intelección de una realidad personal; la intelección de una realidad puramente espiritual, si es que es posible, es distinta a la intelección de una realidad histórica, por más espiritual que sea; la intelección de una realidad constitutivamente social es distinta a la intelección de una realidad a-social. De modo que el carácter social de la historia de la salvación o del reinado de Dios, asunto de la teología cristiana, determina de algún modo su propio proceso de intelección. Sea en la medida en que se enfrenta con una realidad constitutivamente social, sea en la medida en que necesita de mediaciones teóricas capaces de aprehender y formular de modo consecuente esa realidad en su totalidad, también en lo que tiene de social.

El carácter social de la teología tiene que ver aquí, por tanto, con su ámbito de realidad (dimensión social de la historia de la salvación o del reinado de Dios), en cuanto determinante de su proceso de intelección, en el sentido antes explicitado.

\subsection{Finalidad o carácter interesado de la teología}

Pero, además de tratar de una realidad que tiene una dimensión social constitutiva y en cuanto tal determina su proceso de intelección como un proceso intrínsecamente social, la teología tiene una finalidad o un interés social inherente: es una actividad socialmente interesada; responde a intereses sociales concretos, más o menos explícitos y/o legítimos.

Ante todo, eso es un hecho. No hay cómo negar el carácter socialmente interesado de la teología. Abierta o veladamente, consciente o inconscientemente, ella responde o corresponde a determinados intereses sociales y está en conflicto con otros tantos intereses igualmente sociales: legitimándolos o deslegitimándolos, promoviéndolos o confrontándolos, facilitándolos o dificultándolos. Todo esto ocurre tanto tratándose de cuestiones o problemas más explícitos y directamente sociales (propiedad, cuestiones de género, medioambiente, relaciones de poder, estructuras de la sociedad y de la Iglesia, pecado social, etc.), como tratándose de cuestiones o problemas aparentemente poco o nada sociales (lenguaje teológico

la otra" (ibid., p. 341). En esta perspectiva es que, al tratar de la "relación entre lugar social y lugar epistémico", esta no puede concebirse sino en el sentido de que "un compromiso político dado permite o posibilita la realización de un discurso teológico correspondiente" (ibid., p. 291). Sea a través de un "sujeto común", sea de un "objeto común" (ibid., p. 294). Boff no percibe que el modo mismo de conocer una realidad cualquiera esté determinado en buena medida por su constitución o que la realidad determine en buena medida su proceso de conocimiento. 
patriarcal e imperial, monoteísmo, estructura y ejercicio del poder en la Iglesia, relación cruz-salvación, etc.).

Sin embargo, además de ser un hecho, es algo inherente a la propia estructura del discurso teológico. En cuanto momento intelectivo de una praxis que tiene una dimensión social fundamental, la teología responde o corresponde a los intereses inherentes a esa praxis: sea en cuanto la aprehende, sea en cuanto está a su servicio. Además de proceder de una praxis socialmente interesada, acaba favoreciendo los intereses inherentes a esa praxis, en la medida en que "se convierte en favorecedora o desfavorecedora de determinadas fuerzas sociales" 26 . No es jamás una actividad socialmente neutra e indiferente, por más objetiva que sea. Primero, porque, tratándose de una realidad socialmente constituida, la objetividad tiene un carácter social intrínseco. Segundo, porque la objetividad de un proceso intelectivo no se contrapone ni niega su carácter de momento de una praxis socialmente interesada.

De facto et de iure, la teología se presenta, por tanto, como una actividad socialmente interesada. La cuestión no es saber si una teología cualquiera está o no al servicio de algún interés social o si es o no por él condicionada o determinada. La cuestión consiste en saber al servicio de qué interés social concreto está una determinada teología o qué interés social concreto la condiciona o determina. Por esta razón, el teólogo debe preguntarse constantemente "a quiénes y a qué conductas favorecen sus reflexiones o quiénes se hallan a gusto con ellas"27. Explicitar el "origen" y el "destino" social de una teología cualquiera es la única forma de evitar y/o superar su proceso de "ideologización"28, es decir, su instrumentalización por intereses sociales poco o nada evangélicos. Esto que vale para el pensamiento en general ${ }^{29}$, vale particularmente para el pensamiento teológico, mucho más propenso a las "desfiguraciones y manipulaciones no siempre conscientes", dado el carácter "aparentemente" inverificable de muchas de sus afirmaciones ${ }^{30}$.

26. Ignacio Ellacuría, "Hacia una fundamentación del método teológico latinoamericano", op. cit., p. 214.

27. Ignacio Ellacuría, "La teología como momento ideológico de la praxis eclesial", en Escritos teológicos, I, op. cit., pp. 163-185, 167.

28. Ignacio Ellacuría, "Hacia una fundamentación del método teológico latinoamericano", op. cit., p. 211.

29. "El conocer humano tiene así una estricta dimensión social no solo por su origen, sino también por su destino. Lo que se necesita, entonces, para no caer en oscuras ideologizaciones es llevar la hermenéutica hasta el análisis crítico y el desenmascaramiento, cuando sea preciso, de los orígenes sociales y de las destinaciones sociales de todo conocimiento" (ibidem).

30. Ignacio Ellacuría, "La teología como momento ideológico de la praxis eclesial", op. cit., p. 165. "Las afirmaciones más abstractas pueden resultar a veces la expresión religiosa de una situación, cuya verdad es todo menos religiosa. El discurso religioso 
El carácter social de la teología se refiere, aquí, a los intereses sociales (de facto et de iure) inherentes a la propia actividad teológica, en cuanto momento de una praxis socialmente interesada y en cuanto favorecedora o desfavorecedora de determinados intereses sociales, más o menos explícitos y/o evangélicos.

\subsection{Carácter eclesial/institucional de la teología}

Profundamente vinculada a la problemática de los intereses del quehacer teológico, está la problemática de su carácter eclesial/institucional. Además de responder o corresponder a determinados intereses sociales (origen y finalidad), lo hace de modo socialmente estructurado (comunidad eclesial) y en interacción o conflicto con otros grupos o fuerzas sociales (sociedad).

La teología es una actividad intrínsecamente eclesial, no necesariamente eclesiástica. Está siempre, directa o indirectamente, vinculada a la comunidad eclesial y por ella es mediada. No es una actividad absolutamente independiente o autosuficiente. Sin el movimiento desencadenado por Jesús de Nazaret, la Iglesia $^{31}$, no habría teología cristiana. Por más autónoma que sea, en cuanto actividad estrictamente intelectiva, la teología es un momento de una praxis eclesialmente vivida y, en cuanto tal, es por ella configurada incluso cuando esa configuración se caracterice, desde el punto de vista evangélico, como desfiguración. De hecho, el carácter eclesial/institucional de la teología no es indiferente al quehacer teológico en cuanto tal: "La actividad teológica está condicionada y puesta al servicio no solo de la fe, sino de una institución eclesial" ${ }^{32}$ que, en cuanto institución, tiene sus intereses propios, más o menos evangélicos.

puede ser la mistificación del discurso económico y político, y eso no solo cuando fetichiza realidades históricas determinadas, haciendo de ellas cosas divinas o diabólicas, sino, incluso, cuando aparentemente no habla más que de Dios y de lo divino. Sin llegar a la exageración de pensar que todo discurso teológico es solamente esto, cabe siempre la pregunta y la sospecha de cuánto de esto hay en todo discurso teológico. La teología de la liberación, por ejemplo, reconoce muy explícitamente el carácter político de su discurso y su intención histórica dentro de la praxis social, con lo cual evita, en principio, la mistificación, pues abre su juego a toda suerte de críticas y correcciones. No así otros tipos de teología que no se han preguntado todavía por el carácter político de sus afirmaciones" (ibid., p. 166).

31. Aunque Jesús no sea el fundador de la Iglesia cristiana, en el sentido de querer explícitamente romper con la religión judía y crear una nueva religión (institucional, jurídica y jerárquicamente estructurada), es, sin duda alguna, su fundamento y la razón última de su existencia ( $C f$. Medard Kehl, A Igreja: uma eclesiologia católica, São Paulo: Loyola, 1997, pp. 241-249; Casiano Floristán, "Igreja", en Casiano Floristán Samanes y Juan José Tamayo-Acosta, Dicionário de Conceitos Fundamentais do Cristianismo, São Paulo: Paulus, 1999, pp. 354-362).

32. Ignacio Ellacuría, "Hacia una fundamentación del método teológico latinoamericano", op. cit., p. 214. 
Intereses que condicionan de alguna forma no solo el quehacer eclesial, sino también su momento más propiamente intelectivo, esto es, la teología.

Ese carácter eclesial/institucional de la teología, a su vez, la convierte, a través de la institución a la cual sirve, "en favorecedora o contradictora de determinadas fuerzas sociales"33. La comunidad eclesial está inserida en una totalidad histórico-social e interactúa positiva y/o negativamente con otras organizaciones y fuerzas sociales, configurándolas y siendo por ellas configurada. Y nada de eso es indiferente al quehacer teológico propiamente dicho. Como actividad intrínsecamente eclesial y en cuanto inserida en un proceso social más amplio y complejo, la teología se va configurando como un quehacer doblemente social: es condicionada eclesial y socialmente; está al servicio de la comunidad eclesial y, a través de ella, interactúa positiva o negativamente con otras fuerzas sociales. Ese carácter social de la teología adquiere mayor visibilidad y gana mayor relevancia, como veremos un poco más adelante, en sociedades en las cuales los intereses sociales son más antagónicos y los conflictos sociales más intensos y constantes.

El carácter social de la teología tiene que ver, aquí, por tanto, con su eclesialidad e institucionalidad y, a través de esta, con su interacción con las otras fuerzas sociales: condicionándolas o siendo por ellas condicionada; favoreciéndolas o desfavoreciéndolas.

\subsection{Mediaciones teórico-conceptuales de la teología}

Además de tratar de una realidad socialmente constituida e interesada y de ser una actividad intrínsecamente eclesial/institucional, la teología necesita de mediaciones teórico-conceptuales; es mediada por un conjunto de posibilidades teóricas disponibles que se constituyen como "resultado de una marcha histórica y representan el sustrato desde el cual se piensa" ${ }^{34}$.

Por un lado, el proceso de intelección se desenvuelve siempre dentro de una tradición concreta, de un modo concreto de vida, de una cultura, de una civilización que funciona como una especie de "medio intelectivo", "campo intelectivo", "matriz cultural" o "estructura ideológica" que lo condicionan positiva (facilitándolo,

33. Ibidem. "No puede negarse que la institución eclesial es una fuerza social. Prescindiendo ahora de toda consideración de fe, es una institución formada por millares de hombres enlazados entre sí dentro de un orden jerárquico, que tiene una doctrina propia y múltiples canales de acción frente a otras fuerzas sociales" (Ignacio Ellacuría, "Teología de la liberación frente al cambio socio-histórico en América Latina”, en Escritos teológicos, I, op. cit., pp. 313-353, 328).

34. Ignacio Ellacuría, "Hacia una fundamentación del método teológico latinoamericano", op. cit., p. 209. 
posibilitándolo) o negativamente (dificultándolo, impidiéndolo) ${ }^{35}$. "Lejos de ser algo neutro, igual para todos los hombres, el conocimiento es una capacidad humana sometida a los avatares del tiempo, de la cultura, de la historia, etc."; "es relativo a la cultura y a la lengua", e incluso, "a los distintos grupos sociales" ${ }^{36}$. Así, por ejemplo, en cuanto el modo occidental-europeo de lidiar con situaciones paradójicas tiene una estructura más disyuntiva $(\mathrm{o}, \mathrm{o})$, muchas culturas asiáticas tienen un modo más conjuntivo de lidiar con las mismas situaciones (tanto, como; no solo, sino también), lo que puede sonar al oído occidental-europeo como un relativismo peligroso ${ }^{37}$. El propio modo de afirmación (logos) tiene estructuras distintas. De cara al logos predicativo (A es B), típico de las lenguas indoeuropeas, está el logos nominal o constructo (A, B), típico de lenguas como el hebreo, el chino y muchas lenguas indígenas.

El logos nominal tiene la ventaja de entender la realidad de un modo más estructural que atomista. El esquema A, B afirma más enfáticamente la unidad entre los dos términos. El logos predicativo, en cambio, al interponer el verbo ser entre A y B, proporciona más bien la imagen de un mundo dividido en realidades independientes que necesitan ser relacionadas extrínsecamente entre sí. ${ }^{38}$

Sin decir que el modo de pensar y el propio logos pueden ser estructurados más de acuerdo al paradigma de la naturaleza o de acuerdo al paradigma de la historia, con enormes consecuencias teológicas, como lo han mostrado, por

35. Ignacio Ellacuría, Filosofía de la realidad histórica, op. cit., p. 295. En este contexto, Zubiri habla de la "sociedad" como "un medio de intelección": "No es algo que pertenece a lo inteligido, pero es desde luego algo que hace ver lo inteligido de una manera peculiar. Más aún, en medios distintos, las mismas intelecciones pueden tener modalidades distintas. Y no me refiero simplemente al medio social en general, sino inclusive a medios sociales especiales, por ejemplo, un gremio [...] No es lo mismo inteligir algo en un medio social (general o especial) que inteligirlo en un medio religioso. La sociedad en sus diversas formas, la religión, etc. son, desde ese punto de vista, no lo que inteligimos, sino algo que nos hace inteligir las cosas. En diferentes medios se ven las cosas de distinta manera" (Xavier Zubiri, Inteligência y logos, Madrid: Alianza Editorial, 2002, pp. 75 y s.).

36. Antonio González, Introducción a la práctica de la filosofía, op. cit., p. 48.

37. $C f$. Robert J. Schreiter, Abschied vom Gott der Europäer. Zur Entwicklung Regionaler Theologie, Salzburgo: Anton Putest, 1992, p. 28.

38. Antonio González, Introducción a la práctica de la filosofía, op. cit., p. 83; cf. Xavier Zubiri, Sobre la esencia, op. cit., pp. 345-356; e Inteligencia y logos, pp. 151-171; Ignacio Ellacuría, Principialidad de la esencia en Xavier Zubiri, Madrid: Ad modum manuscripti, 1965, pp. 403-442; y "La idea de estructura en la filosofía de Zubiri”, en Escritos filosóficos, II, San Salvador: UCA Editores, 1999, pp. 445-513, aquí pp. 452-456; Ricardo Espinosa Lolas, "El logos nominal constructor en el pensamiento de Zubiri”, The Xavier Zubiri Review, 3 (2000/2001), pp. 121-132. 
ejemplo, los conflictos cristológicos ${ }^{39}$. Todo eso revela aspectos esenciales del carácter social e histórico de las formulaciones teóricas. Estas responden siempre, en mayor o menor medida, a determinados modos de vida.

Por otro lado, y profundamente vinculado a lo que fue dicho anteriormente, no se puede olvidar que el lenguaje o los conceptos utilizados para una formulación teórica cualquiera están intrínsecamente vinculados a una determinada mentalidad (Zubiri) ${ }^{40}$, a un uso concreto, a una determinada forma de vida (Wittgenstein) ${ }^{41}$. Basta tomar como ejemplo el sentido de expresiones tan centrales y decisivas en la teología como "materia" y "espíritu", "cuerpo" y "alma". Estas pueden ser comprendidas tanto en una perspectiva dualista (realidades completas y contrapuestas), más típicamente griega, como en una perspectiva unitaria o estructural (aspectos o dimensiones de una totalidad), más típicamente bíblica con todas las consecuencias que eso acarrea para el conjunto

39. Ignacio Ellacuría, "La historicidad del hombre en Xavier Zubiri”, en Escritos filosóficos, II, op. cit., pp. 199-284, aquí pp. 199-212 y 279-284; "Historia de la salvación”, en Escritos teológicos, I, op. cit., pp. 597-628, aquí pp. 597-602; y "Carácter político de la misión de Jesús”, en Escritos teológicos, II, op. cit., pp. 13-31, aquí pp. 14-17. Paradigmático en ese sentido es el conflicto que terminó en una Notificación por parte de la Congregación para la Doctrina de la Fe sobre algunos puntos de la cristología de Jon Sobrino. Cuando se analiza más atentamente los puntos abordados en la Notificación y, sobre todo, su formulación, lo que se constata, como bien observó el teólogo alemán Peter Hünermann, es una presentación condensada de la “cristología neo-escolástica como criterio para la teología actual” (Peter Hünermann, "Moderne Qualitätssicherung? Der Fall Jon Sobrino ist eine Anfrage an die Arbeit der Glaubenskongregation", en Knut Wenzel (ed.), Die Freiheit der Theologie. Die Debatte um die Notifikation gegen Jon Sobrino, Ostfildern: Mathias-Grünewalde, 2008 , pp. 51-58, aquí pp. 56 y s.).

40. Zubiri insiste, aquí, en la "unidad intrínseca, profunda y radical" entre "expresión" y "mente" que constituye lo que él llama forma mentis o mentalidade. "Por eso es por lo que el decir no es solo un decir 'algo', sino que es decirlo de 'alguna manera', esto es, con ciertos módulos propios de una determinada mentalidad. Dejemos ahora de lado el carácter social y las modificaciones de toda mentalidad y de lo que en ella se dice [...]. Nos basta con afirmar que la estructura del lenguaje deja translucir siempre, en algún modo, unas ciertas estructuras conceptuales propias de la mentalidad"; "en toda estructura lingüística trasparece en algún modo una estructura conceptual" (Xavier Zubiri, Sobre la esencia, op. cit., pp. 345 y s.).

41. Es lo que Wittgenstein expresa con el concepto "juego de lenguaje". "La expresión 'juego de lenguaje' quiere destacar aquí que hablar una lengua es parte de una actividad o de una forma de vida" (Ludwig Wittgenstein, Philosophische Untersuchungen, Frankfurt am Mein: Suhrkamp, 2003, p. 23); "el significado de una expresión es su uso en el lenguaje" (ibid., p. 43). Sobre Wittgenstein, $c f$. Manfredo Araújo de Oliveira, Reviravolta lingüístico-pragmática na filosofia contemporânea, São Paulo: Loyola, 1996, pp. 117-147. 
de la teología ${ }^{42}$. Importa, aquí, insistir en el hecho de que las expresiones o los conceptos utilizados en la elaboración del discurso teológico son inseparables del contexto en el que surgen y de la función y el sentido que desempeñan en ese contexto. "De ahí la importancia esencial y no meramente consecutiva del contexto social y eclesial y del momento histórico para el significado de las tesis teológicas, incluso dogmáticas" ${ }^{\text {"43 }}$.

En cuanto mediada por un sistema de posibilidades intelectivas (estructuras de pensamiento, sistema de conceptos) socialmente constituido y mediado, la teología es una actividad intrínsecamente social.

\subsection{Carácter conflictivo de la teología}

Por fin, el carácter social de la teología tiene que ver con los conflictos más o menos explícitos y/o intensos que caracterizan y acompañan su desarrollo y su elaboración a lo largo de la historia. Ciertamente esos conflictos no se reducen a lo social. Tienen aspectos o dimensiones más formalmente históricos, doctrinales, epistemológicos, etc. Sin embargo, no se puede negar ni minimizar el peso y la importancia de lo social en esos conflictos. Y tanto en el interior de la comunidad eclesial como en la sociedad en general.

No es necesario mucho esfuerzo para reconocer que los conflictos existentes en el interior de la comunidad eclesial son, en gran parte, directa o indirectamente, conflictos de intereses sociales (cuestiones económicas, cuestiones de género, relaciones y estructuras de poder, etc.) y que estos repercuten enormemente en el quehacer teológico. En buena medida, el pluralismo teológico y el conflicto más o menos explícito y/o intenso que lo caracteriza tienen que ver con ese conflicto de intereses sociales en la comunidad eclesial: sea en la medida en que son condicionados y promovidos por determinados intereses sociales,

42. Cf. Ignacio Ellacuría, "Espiritualidad", en Escritos teológicos, IV, San Salvador: UCA Editores, 2002, pp. 47-57; Alfonso García Rubio, Unidade na pluralidade: $o$ ser humano à luz da fé e da reflexão cristãs, São Paulo: Paulus, 2001, pp. 318-360; Gustavo Gutiérrez, Beber no próprio poço: itinerário espiritual de um povo, Petrópolis: Vozes, 1984, pp. 62-83.

43. Antonio González, Trinidad y liberación: la teología trinitaria considerada desde la perspectiva de la teología de la liberación, San Salvador: UCA Editores, 1994, p. 64. Como bien afirma monseñor Aloísio Lorscheider, "el dogma, por lo menos en cuanto a lo que expresa lingüísticamente, se encuentra siempre vinculado a una determinada cultura. Sin conocer aquella cultura, no hay cómo entender la expresión. Entendiendo, por tanto, la cultura subyacente, se comprende el núcleo de la verdad de fe que es perfectamente pasible de ser desvinculado de la cultura de origen y de ser expresado en un nuevo ropaje cultural" (Carlos Tursi y Geraldo Frencken (eds.), Mantenham as lâmpadas acesas: revisando o caminho, recriando a caminhada. Um diálogo de Aloísio cardeal Lorscheider com o Grupo, Fortaleza: UFC, 2008, p. 156). 
sea en la medida en que están a su servicio. Es que el discurso teológico, como vimos, no es algo socialmente neutro o indiferente. Tanto por su origen como por su destino, responde o corresponde a determinados intereses sociales, más o menos conflictivos. $\mathrm{Y}$ ese responder o corresponder condiciona y determina enormemente el propio desenvolvimiento de la actividad teológica. Así, los conflictos en torno de la teología de la liberación, de las teologías feminista, gay, afroamericana, indígena, macroecuménica, entre otras, tienen un carácter o una dimensión social innegable, por más que no se reduzcan a eso. Basta ver el lugar social, los vínculos eclesiales y sociales, los intereses, la relación con las instancias de poder y con las fuerzas dominantes de la sociedad de las personas y de los grupos más directamente envueltos en el conflicto.

Y es aquí, precisamente, donde el conflicto que caracteriza a la teología extrapola los límites de la comunidad eclesial y se insiere en la trama más amplia y compleja de los conflictos de intereses en el conjunto de la sociedad. Por un lado, los conflictos de intereses que condicionan y determinan el quehacer teológico en el interior de la comunidad eclesial no están desvinculados del conflicto de intereses que caracteriza a la sociedad en general. Por otro lado, al responder o corresponder a determinados intereses sociales en el interior de la comunidad eclesial, la teología acaba, directa o indirectamente, (des)favoreciendo a determinados intereses sociales en el interior de la sociedad: sea en la medida en que los (des)legitima teóricamente, sea en la medida en que orienta la actuación de los cristianos y de sus comunidades en una dirección determinada. De ahí el carácter conflictivo de la teología en el conjunto de la sociedad. Este puede ser más o menos intenso y/o explícito, dependiendo de su poder de intervención concreto en el proceso de estructuración de la vida social. El ejemplo más paradigmático, aquí, es, sin duda alguna, la teología de la liberación latinoamericana: una teología que, en palabras de Fidel Castro, "ayuda en la transformación de América Latina más que millones de libros sobre el marxismo" "44; una teología que fue tema de discusión en los altos escalones del Gobierno estadounidense en los años ochenta y que llevó a los asesores del presidente Ronald Reagan a afirmar y recomendar que "la política exterior de Estados Unidos debe comenzar a enfrentar (y no simplemente reaccionar posteriormente) a la teología de la liberación, tal como es utilizada en América Latina por el clero"45; una teología profundamente vinculada a las más diversas luchas populares en todo el continente; una teología, por fin, regada y bautizada con la sangre de centenas de cristianos "famosos" o anónimos, inclusive con la sangre de uno de sus más eminentes y profundos promotores en América Central: Ignacio Ellacuría.

44. Pedro Casaldáliga, Nicarágua: combate e profecia. Edição completa com os anexos sobre Cuba e El Salvador. Petrópolis: Vozes, 1986, p. 172.

45. Comité de Santa Fe, "Documento secreto da política de Reagan para a América Latina”, Vozes, 75/10 (1981), pp. 755-756, aquí p. 755. 
El carácter social de la teología se revela, aquí, en el conflicto de intereses más o menos explícito y/o intenso que la caracteriza, condicionando de algún modo el quehacer teológico y favoreciendo o desfavoreciendo, con él, determinados intereses sociales.

En síntesis, sea por su ámbito de realidad, sea por su interés social, sea por su condición eclesial/institucional, sea por sus mediaciones teórico-conceptuales, sea, en fin, por su carácter conflictivo, la teología tiene una carácter social constitutivo, es una actividad intrínsecamente social, aun cuando no se reduce a eso.

\section{A modo de conclusión}

La insistencia en el carácter social de la teología no significa ninguna descalificación de la actividad estrictamente teórica ni tiene nada que ver con ciertas posturas relativistas que niegan cualquier posibilidad objetiva de acceso intelectivo a la realidad y, por tanto, cualquier posibilidad de verdad objetiva. Significa, simplemente, reconocer y asumir de modo consecuente que toda teoría teológica, en lo que tiene de teoría y en lo que tiene de teológica, tiene un carácter o una dimensión social que la caracteriza y la mensura bajo cierto aspecto. El quehacer teológico es una actividad constitutivamente social: trata de una realidad que tiene una dimensión social, es un quehacer socialmente interesado, eclesialmente situado, posibilitado por estructuras de pensamiento y por sistemas de conceptos socialmente desarrollados, mediados e inseridos en la trama compleja de los conflictos sociales.

Pero eso no es todo. No basta afirmar y explicitar el carácter social de la teología. Es necesario dar un paso adelante y determinar, teórica y teológicamente, el lugar social de la teología. Son dos aspectos de un mismo problema. Ambos se refieren a lo social de la teología. Pero mientras el primer aspecto tiene un carácter más formal y abstracto (insiste en el carácter social de la teología), el segundo aspecto tienen un carácter más concreto y empírico (determina el lugar social de la teología). Nuestra reflexión, aquí, está centrada en el primer aspecto del problema y, por eso mismo, es un abordaje parcial e incompleto; un abordaje abierto y a la espera del desarrollo del otro aspecto del problema: la determinación del lugar social de la teología. Y esto, según las Escrituras, no es otro sino el mundo de los pobres y oprimidos, constituidos, además, en jueces y señores de nuestras vidas, iglesias y teologías (Mt 25,31-46). Pero eso ya es tema o asunto para otro artículo. 